\title{
O papel dos estados de terceiro mundo na concretização dos Direitos Humanos: coordenando conceitos de soberania, globalização econômica e os direitos humanos
}

\author{
The role of third world states in implementation of \\ human rights: coordinating concepts of sovereignty, \\ economic globalization, and Human Rights
}

\author{
George Rezende Moraes* \\ Melina Girardi Fachin**
}

\section{Resumo}

O presente trabalho explora as ambivalências entre os discursos dos direitos humanos e da globalização econômica, tendo em vista que ambos os fenômenos pretendem, via utilização do Estado, estabelecer-se enquanto discurso válido e com força hegemônica. A partir da análise das nuances dos processos de globalização, principalmente daquela de caráter econômico, o trabalho buscará demonstrar, através de revisão bibliográfica, como o Estado foi subvertido para promoção da ideologia neoliberal e como tal mudança na seara internacional e nacional afeta diretamente a promoção dos direitos humanos, principalmente daqueles econômicos, sociais e culturais.

Palavras-chave: Direitos humanos. Globalização. Soberania. Estado.

* Mestrando em Direitos Fundamentais e Democracia, na linha de pesquisa Estado e Concretização dos Direitos: Correlações e Interdependências Nacionais e Internacionais no Centro Universitário Autônomo do Brasil UniBrasil (Curitiba/PR). Curitiba - PR - Brasil. Email: geowrezende@gmail. com

** Doutora em Direito Constitucional, com ênfase em direitos humanos, pela Pontifícia Universidade Católica de São Paulo. Visiting researcher da Harvard Law School. Mestre em Filosofia do Direito Constitucional pela Pontifícia Universidade Católica de São Paulo. É professora da Faculdade de Direito da Universidade Federal do Paraná (UFPR). Curitiba - PR - Brasil. Email: melinafachin@ gmail.com 


\section{Abstract}

This paper explores the ambivalence between the discourses of human rights and economic globalization, considering that both phenomena intend, by the use of the state, to establish themselves as valid and hegemonic speech. From the analysis of of globalization processes frames, especially the economic frame, the study will demonstrate, through literature review how the state was subverted to promote neoliberal ideology, and as such change in the international and national fields, directly affects the promotion of human rights, especially those economic, social and cultural.

Keywords: Human rights. Globalization. Sovereignty. State.

\section{Introdução}

As globalizações, de maneira indiscutível, proporcionam inúmeros avanços nos campos da tecnologia, comunicação, fluxo de conhecimento e de pessoas. Seus desdobramentos, porém, não ficam restritos somente aos benefícios, já que tais vantagens são compartilhadas por um grupo seleto de pessoas originárias de países que ocupam lugar privilegiado na ordem global contemporânea.

Um dos desdobramentos perversos da globalização é perceptível quando o fenômeno adentra no campo da economia - ou seja, globalização econômica -, no qual se constata uma abertura maior das fronteiras do Estado para o livre mercado, a ponto de enlear o propósito do Estado na persecução do bem comum e ideologias capitalistas. ${ }^{1}$

O Direito Internacional hegemônico serve, em grande parte, aos interesses da globalização econômica. O modelo neoliberal que vinha

\footnotetext{
Como demonstrado no relatório do Programa das Nações Unidas para o Desenvolvimento, em que houve declínio no desenvolvimento humano durante os anos de 1990 e 1995. E, ainda, relatórios do Banco Mundial de 2003. ATAIDE, Maria Elza Miranda. O lado perverso da globalização na sociedade da informação. Brasília, v. 26, n. 3, p. , Set. 1997. Disponível em: <http://www.scielo.br/scielo.php?script=sci_arttext\&pid=S0100-19651997000300006\&lng=en\&nr m=iso>. Acesso em 18 ago. 2015.
} 
sendo consolidado durante a década de 1980 encontra seu triunfo com o fim da Guerra Fria, consagrando o desenvolvimento como meta universal do Estado de Direito.

Como será demonstrado no presente trabalho, esse modelo desregulamentado leva a uma confusão entre poder político e poder econômico. Invertem-se as prioridades ao deixar de lado considerações sociais, jurídicas e políticas em favor de liberdades políticas e econômicas. Como resultado, os Estados se converteram para que seus fins atendessem às lógicas econômicas, e não aos propósitos humanos

O alvo principal de todo esse arcabouço internacional são os países subdesenvolvidos, que concentram maior número de pobres. Por coincidência ou não (e o que se constatará no decorrer do presente estudo é que não há coincidência), tratam-se dos países chamados de Terceiro Mundo, que não gozam de outra alternativa a não ser se adequarem a mecanismos internacionais de ajustamentos estruturais.

A gama de efeitos da globalização econômica e o choque entre tendências universalistas e as particularidades de cada Estado afetam diretamente os direitos humanos, uma vez que estes devem se atentar às realidades locais ao mesmo tempo em que são cercados por exigências internacionais (das instituições, de empresas) que vão de encontro à tradicional visão da soberania dos Estados.

Em essência, os direitos humanos visam proteger os seres humanos contra qualquer forma de violência (incluindo aqui a violência do desenvolvimento restrito à análise meramente econômicoquantitativa). Nessa toada, em que o Estado se confunde com o discurso neoliberal capitalista, não se pode mais deixar ao seu plano e deslinde a perseguição dos propósitos internacionais dos direitos humanos, principalmente no campo do desenvolvimento.

Obviamente, a confusão entre papel do Estado, conceitos de soberania, fenômeno da globalização econômica e dúvidas quanto à capacidade de proteção dos direitos humanos encontra terreno nos países de Terceiro Mundo. Nesse ponto, faz-se necessário delinear a utilização do referido termo. 
O Terceiro Mundo (termo que deixou de ser utilizado pós-Guerra Fria $^{2}$ ) retorna para os estudos do Direito Internacional, principalmente através de autores ligados às TWAILs (Third World Approaches to International Law)3 (PRASHAD. 2007, p. 6-7).

O Terceiro Mundo congrega um conjunto de países majoritários que perseguem objetivos comuns e que, unidos em uma só categoria, almejam ter suas vozes ouvidas na arena internacional. Essa categoria é por vezes denominada de "países subdesenvolvidos" ou "em desenvolvimento", em observância aos índices de crescimento econômico (MICKELSON, 1998, p. 356). Tais termos são insuficientes, pois, além de desdobrar em um caráter transitório da sua situação, exclui a colonização como causa da atual conjuntura econômica desses estados (CHIMNI, p. 4).

Nas palavras de Rajagopal (1999, p. 19): "The category 'Third World' can and should be decentered from its geographical moorings of the 'nation' (...) and should be reimagined as a counter-hegemonic discursive tool that allows us to interrogate and contest the various ways in which power is used."

Deve-se encarar então a utilização do termo no presente trabalho para denotar o conjunto de países que se encontram em situação de subjugação às forças hegemônicas de Primeiro Mundo.

Partindo desses pressupostos, a presente reflexão lança-se com o objetivo de refletir, à luz da realidade terceiromundista, como

2 O termo surgiu nesse contexto para diferenciar países capitalistas (Primeiro Mundo), comunistas (Segundo Mundo) e países descolonizados e não alinhados (Terceiro Mundo)

3 Para mais detalhes sobre essa nova abordagem incipiente no Brasil, ver: MORAES, George Rezende; RAMINA, Larissa. Introdução ao estudo das TWAIL: aspectos gerais e conceitos do retorno ao terceiro mundo. In: DOTTA, Alexandre Godoy; GOMES, Eduardo Biacchi (orgs.) Coleção Direito e Ciência na Contemporaneidade. v. 1 Curitiba: Instituto Memória, 2014, p. 265277.

4 Tradução: "A categoria 'Terceiro Mundo' pode e deve ser retirada das amarras geográficas da 'nação' e ser reinventada como ferramenta discursiva contra-hegemônica que nos permite interrogar e contestar as variadas formas como o poder é utilizado. 
coordenar a proteção dos direitos humanos com os revisados conceitos de globalização e soberania.

Para tanto, primeiramente se buscará a fundamentação e conceituação de soberania a partir dos estudos de Francisco de Vitória. Essa conceituação permitirá avançar sobre como o Direito Internacional tornou-se ferramenta da globalização econômica.

Por fim, será verificado como se dá a relação dos direitos humanos com o Estado. Verificar esse entrelaçamento faz-se primordial, pois o discurso protetivo dos direitos humanos surge e insurge-se contra o Estado como o maior violador de direitos, ao passo que deposita nesse mesmo ente a confiança na persecução da sua proteção. Esse relacionamento se mostra ainda mais tenso, dúbio, esquizofrênico e frágil no momento em que a missão do Estado foi encharcada e transformada por interesses que não compreendem a pessoa humana.

\section{A fundamentação da soberania: legitimação da colonização}

O desenvolvimento doutrinário do Direito Internacional surge ainda na Idade Média, sob a forma de uma primeira caracterização e fundamentação dos Estados enquanto entes soberanos e sua diferenciação em relação a outras nações que não possuíam essa mesma característica.

A Igreja Romana e o Império digladiavam entre si pelo poder político supremo, e o princípio da soberania é o ponto fulcral para a distinção entre o Estado e os demais poderes rivais. Nas palavras de Bonavides (2001, p. 158):

Dois gládios se defrontam, duas ordens se hostilizam: a ordem temporal e a ordem espiritual, a coroa e o sacerdócio, Cristo e César. [...] O princípio da soberania começa historicamente por exprimir a superioridade de um poder, desembaraçado de quaisquer laços de sujeição. Tomavase a soberania pelo mais alto poder [...] traço essencial com que distinguir o Estado dos demais poderes rivais, que the disputavam a supremacia no curso do período medievo. 
O grande teórico da soberania é Jean Bodin, que a entendia como um critério existente para identificação de República ${ }^{5}$ anterior ao estabelecimento de qualquer instituição. Soberania, portanto, em sua concepção, é necessária na definição de cidadania enquanto força submetida ao poder soberano. O poder soberano detém poderes, como: julgar em última instância, promulgar e revogar as leis (legislar), declarar a guerra e concluir a paz, e atribuir penas. Para identificar o detentor desses poderes, basta verificar quem é o soberano, que pode ser uma só pessoa (monarquia), um grupo de pessoas (aristocracia) ou a maioria dos cidadãos (democracia) (BARROS, 1996, p. 142-146).

Porém, para Jean Bodin, o Estado encontra limites em leis divinas ou naturais (DELBRUECK, 1982), devendo o verdadeiro monarca submeter os cidadãos e magistrados, bem como a si próprio, a tais limites (BARROS, 1996, p. 147). Bodin forneceu elementos necessários para a emergência da concepção moderna de Estado-nação. O Estado moderno, ao tomar para si o monopólio do uso da força enquanto a nega para os não-Estados, é a forma que a soberania assume.

$\mathrm{Na}$ tentativa de fundar o Estado soberano com bases racionais, Hobbes racionaliza o Estado como um ente personificado das vontades de todos os indivíduos, podendo se utilizar de toda a força para a paz e defesa comum (FERRAJOLI, 2002, p. 19).

A moderna noção de soberania é entendida como uma característica essencial na constituição do sistema internacional, e é também um conceito relativo, estando sujeito a limitações de que o sistema necessite (DELBRUECK, 1982, p. 120).

Ferrajoli, em sua obra sobre as origens jusnaturalistas da ideia de soberania, verificou, dentre as suas possíveis dimensões, a externa e a interna. ${ }^{6}$

Entendida como o conjunto de famílias ou de colégios submetidos a um só e mesmo comando.

A externa se manifesta nas relações de um Estado com terceiros, sendo vedada qualquer intervenção e subordinação, com o Estado totalmente independente em suas ações. Essa, para os historiadores, foi teorizada antes que a interna, servindo para seu fundamento. A soberania interna se manifesta nos relacionamentos com seus internos, dotando o Estado com uma força que predomina sobre as vontades dos indivíduos. 
A soberania externa foi a primeira a ser teorizada, tendo Francisco de Vitoria como fundamental no processo. É esse o principal fulcro de análise de Ferrajoli. No desenvolvimento dos seus clássicos estudos sobre o tema, objetivava uma finalidade prática, qual seja, dar às conquistas das novas terras pela Espanha um fundamento jurídico (FERRAJOLI, 2002, p. 6); via a criação de um novo ordenamento internacional deslocado da lei divina e do seu administrador, o Papa, para a soberania e o direito natural secularizado (ANGHIE, 2004, p. 18).

Três ideias basilares identificadas por Ferrajoli (2002, p. 6-13) norteiam o pensamento de Francisco de Vitoria.

A primeira é que a ordem mundial é uma sociedade natural de Estados soberanos (o Estado não mais soberano e livre é subordinado aos direitos das gentes internamente e externamente, e a humanidade é sujeito de direito).

A segunda ideia é a de que há uma série de direitos naturais dos povos e Estados que deveriam ser respeitados, juntamente com um rol de direitos. ${ }^{7}$

A terceira ideia identificada por Ferrajoli passa a fundamentar a guerra como uma sanção jurídica às ofensas sofridas (a guerra é lícita e necessária, já que os Estados, submetidos ao direito das gentes, não podem recorrer a um tribunal - visto que ausente - para ver seus argumentos impostos).

Desse retrospecto histórico, verifica-se que a doutrina da soberania foi utilizada para legitimar a dominação eurocêntrica (livre, enfim, das amarras cristãs) através da colonização e exploração do resto do mundo, em nome de valores proclamados universais. Primeiro, para evangelizar; depois, civilizar; e, por fim, homogeneizar a modernidade com valores ocidentais (FERRAJOLI, 2002, p. 16).

Vitoria os alia a outros direitos que ressaltam a assimetria no relacionamento entre os povos, tal qual o direito de evangelizar e o direito-dever de censura fraternal dos bárbaros, que desbocam no direito dos espanhóis de recorrerem a medidas extremas caso os índios não aceitem pacificamente suas boas razões. 
Durante o século XIX e a primeira metade do século $X X$, verificase a afirmação na Europa de um Estado nacional liberal-democrático, fundado na limitação dos poderes soberanos, sujeito à lei, ao passo que se liberta nas relações externas de quaisquer freios normativos. Em outras palavras, na concepção de Ferrajoli, quanto mais a soberania interna é limitada, mais é legitimada nas relações externas com outros Estados "incivis” (FERRAJOLI, 2002, p. 35).

É nas atrocidades cometidas durante a Segunda Guerra Mundial que a soberania externa alcança sua potencialidade máxima expansionista, no mesmo momento em que encontra sua falência. A Carta da ONU, de 1945, e a Declaração Universal dos Direitos Humanos, de 1948, teriam o condão de tornar a absolutização da soberania externa inconsistente com seus propósitos (FERRAJOLI, 2002, p. 40).

Ademais, a arena internacional defronta-se com o surgimento de diversos outros organismos e tratados que adentram na complexidade de temáticas globais, principalmente nos campos econômicos, com vista a regular as relações entre os países. Nas palavras de Philip Cerny (2014 p. 624):

Patterns of collective action by and among states in the international system, shaped by complex (mainly economic) interdependence, lead to formation of both informal and formal structures and institutions which can take on an autonomy of the own at the international level. ${ }^{8}$

Nesse cenário, há um duplo efeito aos Estados. O primeiro deles é que o desenvolvimento dos direitos humanos impõe obrigações e deveres ao Estado, enquanto na seara econômica sua autossuficiência é mitigada e a interdependência é majorada. O Estado obriga-se a dialogar com outras nações, e, nesse diapasão, sua forma de

8 Padrões de ação coletiva por e entre os Estados no sistema internacional, moldados pela complexa (principalmente econômico) interdependência, leva à formação de ambas as estruturas e instituições, formais e informais, que podem assumir uma autonomia internacionalmente. 
organização é transcendida pelas globalizações com maior impacto de ordem econômica (ROBINSON, 2002, p. 210).

As globalizações não mostram seus efeitos somente no âmbito de interpendências doméstica e interações dos Estados, mas também provoca uma reconfiguração de tais entes. Dessas transformações, surgem, invariavelmente, questionamentos acerca de quais interesses o Estado visa garantir: do mercado economicamente globalizado ou seu fim precípuo de defesa dos cidadãos.

\section{Globalização econômica e o direito internacional}

A atualidade parece levar à constatação de que não há qualquer controle do mundo e que nenhuma localidade pode se locupletar enquanto voz da humanidade. Essa nova percepção é articulada sobre o conceito de globalização, que transmite a ideia de um "caráter indeterminado, indisciplinado e de autopropulsão dos assuntos mundiais" (BAUMAN, 1999, p. 66).

Nesse sentido, haja vista a globalização que cerca as relações internacionais, há quase meio século os cidadãos dos Estados deixaram de ser somente assunto interno e passaram a ser objeto de escrutínio externo, erodindo um aspecto central da soberania (RAJAGOPAL, 2005, p. 224).

A partir da Sociologia, Giddens (1991, p. 76) afirma que as relações sociais são basicamente pautadas em interações locais e distantes por meio do espaço-tempo. A globalização seria o entrelaçamento cada vez maior dos contextos sociais locais com diferentes regiões do globo. Há uma intensificação das relações sociais em escala global e acontecimentos locais são moldados por eventos distantes.

Boaventura de Sousa Santos (1997, p. 14) define globalização não como termo estático e em um só sentido, e sim em observância às dimensões sociais, culturais e políticas que criam conjuntos distintos de relações sociais fundantes de diferentes fenômenos de globalização. 
Alex Seita (1997) afirma que esse processo significa muitas coisas e ocupa muitas dimensões (político, cultural, meio ambiente, filosófico, legal), mas é, acima de tudo, um processo econômico.

Seguindo ainda o pensamento de Boaventura de Sousa Santos (2007, p. 23), há duas globalizações em curso: a globalização hegemônica neoliberal, constituída pela nova fase do capitalismo, e a globalização contra-hegemônica "dos movimentos e organizações que, mediante articulações locais, nacionais e globais, lutam contra as desigualdades, a opressão, a destruição dos modos de vida e do meio ambiente, causados ou agravados pela globalização hegemônica".

A globalização hegemônica tem a seu serviço instituições diversificadas e poderosas. De outra mão, a globalização contrahegemônica ainda caminha sob formas embrionárias de instituição, dentro do Fórum Mundial Social e na Assembleia dos Movimentos Sociais (SANTOS, 2007, p. 23).

Ainda que se possa negar o fim da Guerra Fria como sendo "o fim da história", nas palavras de Francis Fukuyama (1992), o seu término desarrolhou e não há espaço para negações. Uma intensificação no processo de transformação do capitalismo liberal como ideologia marcante nos Estados fez emergir uma reformulação na noção de Estado em sua relação com o mercado.

A globalização econômica é vista por muitos estudiosos, principalmente os economistas, como forma de aumento dos negócios, investimentos e competição, sendo benéfica para o mundo todo. Esses elementos seriam essenciais para a promoção do desenvolvimento econômico, ao fazer com que economias em desenvolvimento funcionem de maneira mais eficiente, refletindo na produção e ciência, e erradicando a pobreza. Por fim, todos os direitos previstos no pacto dos direitos econômicos, sociais e culturais seriam garantidos quando observadas tais diretrizes do mercado (ASKOLA, 2010, p. 105).

Porém, essa visão simplista ignora a verdadeira forma de atuação da economia, já que, na prática, o acesso aos bens se dá de maneira desigual. Tal temática será tratada no tópico seguinte. 
O neoliberalismo opera no plano político mudanças sem precedentes, tendo o mercado extrapolado sua seara econômica para colonizar o Estado e a regulamentação dos direitos humanos (SANTOS, 1997, p. 51).

Os direitos humanos são uma das únicas áreas do Direito Internacional que estão comprometidas com a proteção da dignidade da pessoa humana em todos os aspectos. A globalização de feição econômica promove desigualdades que desafiam a integridade dos direitos humanos, principalmente porque se utiliza destes como forma de promover a si mesma (ANGHIE 2004, p. 256).

Para Anghie (2004, p. 257), os direitos humanos foram inundados por uma nova roupagem do discurso civilizacional de Francisco de Vitória, em que se busca levar aos países mecanismos democráticos e políticas transformadoras ligando forçosamente o direito internacional dos direitos humanos com o desenvolvimento, principalmente nos países de terceiro mundo.

A operacionalização do aludido desenvolvimento meramente econômico e neoliberal no âmbito internacional ocorre de maneira complexa e contraditória, tal qual pode ser identificado nas palavras de Anand (2008. p. 90):

The only way the poor countries can better their lot is by increasing production and by industriallzation. But this requires capital. By a rough rule of thumb, economists tell us that to secure one unit of income you have to invest three times as much capital. Here they are again caught in a dilemma. Capital can be formed only by saving, by not consuming. ${ }^{10}$

10 Tradução: "A única maneira de países pobres melhorarem sua sorte é através do crescimento da produção pela industrialização. Porém, para tanto, precisa de capital. Utilizando de uma regra básica, os economistas nos dizem que, para garantir uma unidade de renda, você precisa investir três vezes mais capital. Aqui é onde os países se encontram em um dilema. Capital somente por ser constituído pela poupança, ou seja, não consumindo." 
É no Terceiro Mundo que a dominação neoliberal encontra maior pujança, principalmente no avanço de três instituições econômicas internacionais: a Organização Mundial do Comércio (OMC), o Banco Mundial e o Fundo Monetário Internacional (FMI). Essas novas instituições internacionais e transacionais conectaram os Estados soberanos ao transformar soberania em um compartilhamento de poder, estando elas no cerne da emergência dessa nova governança global denominada "império"11 do capitalismo" (HELD, 2000, p. 12).

Sem a pretensão de adentrar no funcionamento e estrutura das instituições, cabem aqui algumas considerações superficiais. As instituições financeiras internacionais possuem como principal característica, no que tange aos seus efeitos, o entrelaçamento entre a ajuda financeira e a readequação de condutas pelos países. Os programas de reajustamentos estruturais das suas economias envolvem desde reduções nos gastos governamentais e liberalização da economia até privatizações (ANGHIE, 2004, p. 259).

Joseph Stiglitz (2002, p. 52) afirma que o FMI, em sua função precípua de manutenção da estabilidade econômica que ignora o pensamento dos países que o procuram, "parece mais um administrador colonial" na imposição dessas condicionalidades.

É sob o manto do intuito de uma good governance ${ }^{12}$ que tais instituições se articulam entre os seus fins e o discurso ético de eliminação da pobreza. A good governance é um forte apelo universal e envolve "the creation of a government which is, among other things, democratic, open, accountable and transparent, and which respects

11 O autores destacam que a utilização do termo não é metafórica. Um império é caracterizado pela ausência de limites. Primeiro, propõe um regime que domina todo o espaço geográfico. Segundo, para o autor, o império atual não um é um regime transitório, e sim um uma ordem que tende à perpetuidade. Terceiro, opera em todos os âmbitos sociais, desde a vida social até mesmo a natureza humana. Por fim, ainda que a prática do império seja sanguinária, seu discurso sempre será de dedicação à paz.

12 Apesar de o termo ser, em tradução literal, "boa governança", é preferível, no trabalho, a utilização do termo no original, em inglês, por não contar ainda na língua portuguesa com uma tradução feita pelos doutrinadores. 
and fosters human rights and the rule of law" (ANGHIE, 2004, p. 245248). Nesse cenário, a ausência de desenvolvimento atinge a good governance.

Para Jack Donnelly (2004, p. 11-15), os ajustes estruturais impostos por instituições internacionais para concessão de empréstimos e subsídios não são causas para erosão da soberania de determinado Estado. Ele afirma que não há qualquer coerção, mesmo que advenha de um desespero interno ou pressão externa, sendo a voluntariedade das partes somente questionada se houvesse ameaça ou uso da força. Para Donnelly, a soberania é uma autoridade para decidir entre alternativas e, enquanto a possibilidade de eleição entre ações subsistir no Estado, a soberania não seria infligida.

A globalização econômica estaria a mudar o caráter do Estado para uma forma transacional orientada pela proteção global (e não nacional) do capital e dos interesses de uma determinada classe.

É esse o entendimento de Cox (1992, p. 27):

[...] subordination of domestic economies to the perceived exigencies of a global economy. States willy nilly become more effectively accountable to a nebuleuse personified as the global economy; and they were constrained to mystify this external accountability in the eyes and ears of their own publics through the new vocabulary of globalisation, interdependence and competitiveness. ${ }^{13}$

Donnelly (2004, p. 23) afirma que, mesmo nesses casos, a ameaça surge a partir das finalidades que o Estado exerce sua soberania. Essas questões versam não sobre a autoridade do Estado, mas sobre as suas capacidades e intenções.

13 Tradução: "Subordinação das economias domésticas às exigências percebidas na economia global. A contragosto, os Estados se tornam efetivamente responsáveis para com essa nebulosa [no sentido de imprecisa] personificada como economia global; e eles são forçados a iludir essa responsabilidade externa nos olhos e ouvidos do seu próprio povo pelo novo vocabulário da globalização, interdependência e competitividade." 
Entretanto, para Richard Falk, o Estado é cada vez mais globalizado e internacionalizado desde que afastou os olhos do seu território para orientar-se politicamente com base no exterior. Assim, "o Estado passa (...) a funcionar como instrumento de forças de mercado regionais e globais não territoriais, como uma entidade manipulada por corporações e bancos transnacionais e, com uma frequência crescente, também por agentes financeiros" (2001, p. 77).

Verifica-se, à luz dos fatos aqui apresentados, que os direitos humanos nasceram enxergando o Estado como o maior violador de direitos e, por isso, age como meio de defesa do particular frente ao Leviatã, porém, ao mesmo tempo, reconhece que os direitos somente podem ser materializados via atuação do poder público. Assim, cabe questionar a possibilidade de entrelaçamento desse Estado transnacionalizado, que visa atender aos interesses do mercado com o discurso e a efetividade dos direitos humanos.

\section{Estado e direitos humanos no mundo globalizado}

Entender o fenômeno da globalização econômica como resultado de relações conflituosas explica por que há um vencedor e um vencido. Para Richard Falk (2001, p. 77), "a globalização é o processo pelo qual determinada condição ou entidade local estende sua influência a todo o globo e, ao fazê-lo, desenvolve a capacidade de designar como local outra condição social ou entidade rival". Em outras palavras, aquilo que é tido como globalização é a vitória da expansão de determinada particularidade local.

Os direitos humanos acabam por enfrentar problemas na sua efetivação, tendo em vista a incompatibilidade de seus valores básicos colidirem diretamente com os valores e determinações da transnacionalização do mercado, qual seja, eficácia, produtividade e competitividade.

O cálculo econômico e a razão produtiva, em outras palavras, revelam-se potencialmente incompatíveis com os 
princípios básicos de convivência e sociabilidade no âmbito de formas organizacionais e institucionais dotadas de um mínimo de legitimidade jurídica e equilíbrio social. (FARIA, 1997, p. 30).

Os direitos humanos, enquanto discurso da dignidade da pessoa humana, convivem com uma realidade em que grande parte da população não é sujeito da sua tutela.

Boaventura de Sousa Santos (2013, p. 42-50) parte, então, em busca de uma concepção contra-hegemônica dos direitos humanos. Inicia com questionamentos da sua matriz ocidental, que produziu certos consensos ilusórios quanto ao discurso, sendo um deles a ilusão de ser antiestatal.

Historicamente, o discurso dos direitos humanos surge como uma exigência, contra o Estado, de uma parcela da sociedade que não pertencia à classe dominante, avançando até a consolidação da ideia de que, para respeitar os direitos humanos, o Estado deve abster-se de violar direitos (SANTOS, 2013, p. 51). Essa visão é a que Rajagopal (2005, p. 224) denomina de minimalista, pois quanto mais se amplia o rol de direitos tutelados, menor fica o Estado.

Nas palavras de Boaventura de Sousa Santos (2013, p. 52):

A promiscuidade crescente entre o poder político e o poder econômico, a hipertrofia das funções de acumulação do Estado em detrimento das funções de confiança e de hegemonia, as condicionalidades impostas por agências financeiras internacionais, o papel preponderante das empresas multinacionais na economia mundial, a concentração da riqueza, tudo isto tem contribuído para reorganizar o Estado, diluindo sua soberania, submetendo-o à crescente influência de poderosos atores econômicos nacionais e internacionais, fazendo com que os mandatos democráticos sejam subvertidos por mandados de interesses minoritários, mas muitos poderosos. 
Com a contínua construção e fundamentação dos direitos sociais e econômicos, também é exigida do Estado uma postura positiva prestacional, centrando-se de qualquer forma no Estado.

Cabe ressaltar que, no âmbito interno, o Estado não vem perdendo sua pujança de controle, o que pode ser observado pela ampliação de funcionários e maior burocratização (ARENDT, 1970) ${ }^{14}$ para a criação e constrição dos direitos (RAJAGOPAL, 2005, p. 225).

Obviamente, há grupos ganhadores em cima desse processo desregulamentador, porém, o número de perdedores supera o de ganhadores. Nas palavras de Müller (2000, p. 32): "conforme evidenciam a agudização da miséria individual e o surgimento de regiões inteiras, de países inteiros (como e.g. na África) por assim dizer esquecidos pelo mercado mundial. Então os frutos da globalização nem chegam a ser distribuídos, muito menos distribuídos adequadamente".

O modelo de globalização econômica atualmente lastreado não atende ao verdadeiro intento do desenvolvimento preconizado pelos direitos humanos, uma vez que, como visto anteriormente, "privatiza os lucros e socializa as perdas" (FACHIN, 2015, p. 269).

Esse processo é denominado por Bengoa (1997, p. 23) de "globalización de la pobreza", sendo caracterizado pelo reaparecimento de uma classe menos favorecida em países desenvolvidos e pelo surgimento dos bolsões de pobreza. Nos países latino-americanos, verifica-se o afastamento do Estado de Bem-Estar e o aparecimento da pobreza no centro dos debates. E nos países em situações precárias, a realidade é deteriorada pelo incremento de pessoas que vivem nessa situação

Os marginalizados econômicos não são vistos mais como dotados de direitos subjetivos que possibilitam o exercício dos seus direitos

14 Hannah Arendt observa que essa burocratização constitui - diferentemente da monarquia e oligarquia, em que o homem dominava o homem - uma nova forma de dominação, na qual não se pode identificar um responsável. É o "domínio de ninguém". 
humanos, o que não significa dizer que foram esquecidos pelos deveres legais. Com a ampliação das desigualdades sociais, dos bolsões de miséria, do aumento da desobediência e da criminalidade, o Estado tende a assumir funções punitivas (FARIA, 1997, p. 50) em detrimento das econômicas e sociais. Enquanto estas são cada vez mais flexibilizadas, aquelas tomam o caminho oposto (BENGOA, 1997, p. 23).

Os direitos humanos surgem para garantir a igualdade entre todas as pessoas, devendo ser respeitados e exercidos contra os Estados soberanos. Suas convenções e tratados estabelecem direitos para todos os indivíduos, entretanto, as obrigações são criadas somente para os Estados. Por sua vez, os estes se obrigam somente frente aos seus nacionais ou aos estrangeiros que estão em seu território (DONNELLY, 2011, p. 18).

O controle desse ente poderoso - o Estado - se dá em duas frentes pelo direito internacional dos direitos humanos: uma frente positiva, em que há obrigação do Estado em fornecer e atuar na persecução dos direitos humanos; e uma frente negativa, na qual o Estado fica proibido de interferência em esferas privadas, ao passo que deve garantir o direito à liberdade de pensamento, expressão, participação política etc. Ademais, os direitos humanos versam, ainda, sobre a prestação de certos serviços, bens, oportunidade e proteção dos Estados (DONNELLY, 2011, p. 19-20).

A relação entre Estado e direitos humanos conduz a uma aparente "esquizofrenia", utilizando-se do termo de Rajagopal (2005, p. 224), pois se funda numa suspeita profunda do Estado, ao mesmo tempo em que deposita nesse ente a função de defesa dos direitos humanos.

É o que explica Jack Donnelly (2011, p. 23):

In the contemporary world we are taking more seriously the idea that states can be held morally and politically liable at the international level for how they treat their own citizens on their own territory. But sovereign states remain the central mechanism by which contemporary international society seeks to implement internationally recognized human 
rights, as is underscored by the very modest incremental growth in the scope and powers of multilateral human rights institutions in recent years. ${ }^{15}$

O triunfo da ideologia neoliberal é verificado quando setores da sociedade defendem abertamente que, devido à ineficiência do Estado em campos sociais e econômicos, suas atividades econômicas e empresas estatais devem ser privatizadas com redução do Estado, em um duplo processo de dependência cada vez maior do mercado mundial, ao passo que, internamente, desregula a atividade produtiva (BENGOA, 1997, p. 27).

O Estado-nação é afetado também pelo processo de globalização, devido à limitação da sua estrutura normativa. O aparato jurídico dos Estados é erguido sob a égide dos princípios da impessoalidade e da abstração, dentro de um sistema que tende a ser fechado com normas hierarquizadas. Tal arcabouço é demasiado simples e burocrático para comportar ações complexas do mercado econômico globalizado e enfrentar a pluralidade de cenários possíveis (FARIA, 1997, p. 44).

As transformações advindas dessa nova lógica econômica (investimento em escala global, processos de produção multilocal, baixo custo de transporte etc.) exigiram que as economias dos Estados fossem abertas para o mercado mundial, adequando os preços no âmbito doméstico ao âmbito internacional, sempre priorizando uma economia voltada para a exportação. Todas essas implicações visavam a diminuição do papel do Estado na regulação da economia, subordinando-o às agências econômicas multilaterais internacionais (SANTOS, 1997, p. 29-31).

15 Tradução: "No mundo contemporâneo, nós estamos levando mais a sério a ideia de que os Estados possam ser considerados moral e politicamente responsáveis na arena internacional quanto ao modo como tratam seus cidadãos em seus territórios. Entretanto, a soberania estatal continua sendo o mecanismo central pelo qual as sociedades internacionais visam implementar os direitos internacionalmente reconhecidos, como se verifica pelo modesto crescimento no escopo e poderes das agências multilaterais de direitos humanos recentemente." 
Como o Estado não pode deixar todo esse arcabouço de ações transcorrer livremente, sem qualquer tipo de controle, acaba por criar normas jurídicas. Porém, o sistema normativo não é capaz de englobar e positivar toda a complexa mistura de interesses plurais e, por vezes, contraditórios.

Revelam-se igualmente incapazes de regular e disciplinar, guardando coerência sistêmica, fatos multifacetados e heterogêneos. Organizadas sob a forma de um código rigidamente binário (permitido/proibido, legal/ilegal e constitucional/inconstitucional), tais normas padronizadoras revelam-se ineficazes na regulamentação e tratamento de casos muito específicos e singulares. (FARIA, 1997, p. 44).

A integração mundial dos mercados enfraquece o poder de controle sobre fluxos financeiros e aumenta a autonomia da economia, cada vez mais especializada e plural, atingindo diretamente a soberania do Estado.

O capital é produzido e movimentado num espaço econômico internacional que não mais se liga a conceitos territoriais de soberania política. Soberania política que não mais se vincula à soberania econômica (BENAKOUCHE, 1980, p. 81).

Para Faria (1997, p. 48-49), o Estado que se vê impossibilitado de regular, de maneira autônoma, setores sociais e econômicos, uma vez que há fontes diversas do direito, perde também o controle sobre a racionalidade dos seus códigos. Evidencia-se tal fato quando o Estado se encontra obrigado a negociar quais entidades transacionais condicionam investimentos à aceitação de valores, regras e até mesmo solução de conflitos. ${ }^{16}$

16 Explica Faria: "Vem sendo minada pela força constitutiva de situações criadas pelos detentores do poder econômico; e, como consequência, vem sendo substituída pelo veloz crescimento do número de normas privadas, no plano infranacional, à medida que cada corporação empresarial tende a criar as regras de que precisa e a jurisdicizar suas respectivas áreas e espaços de atuação segundo suas conveniências." 
Como consequência da globalização econômica, o debate político passa a ocorrer em territórios e esferas alheias à política do próprio Estado, obrigando seus cidadãos a submeterem-se às decisões tomadas fora da sua esfera de participação, fragmentando a própria cidadania, pilar da democracia e dos direitos humanos.

Tais fatos atingem diretamente a consecução, realização e exigibilidade dos direitos econômicos, sociais e culturais que, ao lado dos empecilhos normativos, reforçam a dificuldade de implementação dos direitos ${ }^{17}$ (FACHIN, 2015, p. 256).

Historicamente, a resistência aos direitos econômicos e sociais pelos países ocidentais tem suas raízes na Guerra Fria. A União Soviética e os países aliados arguiram que os direitos econômicos e sociais seriam primordiais, pois direitos civis e políticos não teriam significado se as pessoas não tivessem suas necessidades básicas atendidas, como alimentação e moradia. Países ocidentais e do Norte, de outra mão, enxergavam os direitos civis e políticos como legais, já que os econômicos e sociais não seriam, na visão deles, possíveis de ser solicitados e exigidos judicialmente (NYAMU-MUSEMBI , 2002, p. 11).

Alterou-se a situação com o fim da Guerra Fria e, desde a Conferência de Viena sobre Direitos Humanos, em 1993, os princípios fundantes dos direitos humanos (interdependência, indivisibilidade e não hierarquia entre os direitos) tornaram-se os mantras do Direito Internacional dos direitos humanos. Apesar da positivação e consolidação dos princípios, os direitos econômicos e sociais enfrentam ainda graus de ceticismo quanto ao seu reconhecimento e efetivação (NYAMU-MUSEMBI , 2002, p. 11).

17 Do ponto de vista jurídico, os direitos humanos e fundamentais, sob uma lógica geracional que coloca determinados direitos como superiores a outros, retira a interdependência dos direitos humanos. Tal fato é corroborado pela divisão dos direitos em dois pactos. O primeiro, que versa sobre os direitos civis e políticos, e o segundo, sobre os direitos econômicos, sociais e culturais. 
O fim da bipolaridade ideológica, como afirmado anteriormente, consagrou o modelo liberal e a afirmação de que ele levaria à liberdade política e à democracia. Aceitou-se de maneira homogênea a necessidade de investimento em países autoritários, violadores de direitos civis e políticos, e que o desenvolvimento econômico era a chave para a mudança. Nos países democráticos, direitos sociais eram imobilizados e o Estado-providência era um empecilho à livre concorrência. Sem as prestações positivas necessárias, o exercício da cidadania é incompleto. ${ }^{18}$

Deve-se romper do ponto de vista jurídico a visão que põe os direitos sociais em uma posição inferior aos demais, devendo aquele rol espelhar a interdependência e interpelação expostas nos diplomas contemporâneos, e não compactuar com a visão retrógrada, bifurcada e arcaica dos direitos, que desbocou em dois pactos distintos para justificar que um direito subjugaria outro (FACHIN, 2015, p. 256).

Ao lado dessa exclusão na vertente jurídica, os direitos econômicos e sociais são obstaculizados na sua efetivação, mormente pela globalização econômica, que, como demonstrado no presente trabalho, transforma os direitos humanos, passando a agir em favor da lógica do mercado neoliberal.

Direitos sociais básicos, como educação e saúde, são transformados em mercadorias, sujeitos à compra e venda, afunilando os sujeitos que poderão acessá-los, para privilegiar somente aqueles com poder de consumo. Deve-se ainda acrescentar o fato de que grupos vulneráveis terão seus direitos violados em maior escala, como mulheres e negros (PIOVENSAN, p. 77).

Essa transformação da lógica mundial é descrita por Friedrich Müller (2000, p. 14) como "governo do mercado", "que retira do povo o

\footnotetext{
18 O conceito de cidadania aqui utilizado é o que defende Marshall. Os direitos civis e políticos são vistos como instrumentos legais para lutas e conquistas dos direitos sociais e econômicos.
} 
poder de decidir sobre o que realmente é capaz de influenciar os seus próprios destinos".

A relativização da soberania estatal, que vem acontecendo desde o início do século $X X$, com agravamento nas últimas décadas, não se trata de mera crise com condão temporário. Em verdade, a relativização possui o intuito de remover características determinantes do Estado Moderno, a fim de transferi-los para entes supostamente impessoais, os quais nada mais seriam que instrumento do mercado (DUARTE, 2013).

Essa globalização, apresentada como inofensiva, elimina tarifas alfandegárias que visam à proteção dos mercados locais, para expô-los à concorrência internacional, difícil de ser enfrentada (MUELLER, 2000, p. 31), ao passo que tais setores integram com celeridade e entusiasmo os benefícios da globalização econômica (BENGOA, 1997, p 22). Müller (2000, p. 31) destaca que os agricultores do Terceiro Mundo são alocados para produzirem com vistas ao mercado mundial, obrigando seu país a importar e se tornar dependente das importações de alimentos.

Tendo em vista que o Estado é o ente chamado para dar cumprimento aos direitos econômicos, sociais e culturais, sua atuação não teria posto em xeque a capacidade de decidir de maneira autônoma os rumos internos desse campo?

$\mathrm{Na}$ luta pela consolidação de tais direitos, designados principalmente ao Estado, a luta contra a extrema pobreza é primaz, "já que que esta per se representa a falência do projeto de justiça social" (FACHIN, 2015, p. 250).

Nas palavras de Piovesan:

Considerando os graves riscos do processo de desmantelamento das políticas públicas sociais, há que redefinir o papel do Estado sob o impacto da globalização econômica. É preciso reforçar a responsabilidade do Estado no tocante à implementação dos direitos econômicos, sociais e culturais. (PIOVESAN, 2014a, p. 61-62). 
Independentemente de toda e qualquer discussão quanto à interação entre os direitos econômicos, sociais e culturais, o Estado e sua responsabilização, é indiscutível que seu papel garante as igualdades (com a não diferenciação - ou discriminação - dos cidadãos ante a lei) econômica, educacional, cultural, de trabalho etc., que se traduzem na necessidade de promover uma maior igualdade de oportunidades. Não é olvidado que o Estado não detém capacidade plena de fornecer todos os direitos (como um trabalho), mas sua obrigação consiste em extirpar formas discriminatórias que impeçam o exercício pleno deles (BENGOA, 1997, p. 28). O acesso deve ser garantindo para a erradicação de injustiças sociais.

A proteção às necessidades básicas de justiça social compõe o processo complexo de múltipla natureza (econômico, social, cultural, político, dentre outros) que representa o direito humano ao desenvolvimento, que tem nos seres humanos o sujeito central do desenvolvimento como ativos participantes e beneficiários do direito ao desenvolvimento, orientado para a equitativa repartição dos melhoramentos que daí resultem. (FACHIN, 2015, p. 250).

A não discriminação e a promoção da igualdade são elementoschave para a efetivação dos direitos humanos e do pleno exercício daqueles referentes aos econômicos, sociais e culturais. Contudo, o modelo de econômico globalizatório hegemônico presente na atualidade é contraditório e oposto ao desenvolvimento humano. O fim inevitável da não sincronização de rumos é a constante produção e reprodução de populações que saem perdendo e não participam da distribuição dos proventos (FACHIN, 2015, p. 254).

Apesar de entendimentos que retiram dos direitos econômicos, sociais e culturais a sua plena e máxima capacidade, a positivação de tais normas estabeleceu "un conjunto de principios elementales que permiten a las personas participar del genero humano, con cierta dignidade", e continua, "establecen el límite ético, la 'frontera ética', entre vivir como personas y el de no vivir como personas" (BENGOA, 1997, p. 25). 
Frente ao processo de globalização econômica, tais direitos devem ser utilizados como limites.

No contexto da globalização econômica, é primordial que atores não estatais incorporem a agenda dos direitos humanos em sua atuação. As agências internacionais devem atuar em observância aos impactos da política econômica na dimensão humana e social, pois, como observado, sua política de condicionalidade para os países de Terceiro Mundo é incompatível com o discurso dos direitos humanos (PIOVESAN, 2014b, p. 62-63).

Como o Estado é enfraquecido e incapaz de realizar os direitos dos seus cidadãos de maneira não discriminatória, o indivíduo passa a identificar-se com comunidades por conta de cor da pele, religião, gênero ou orientação sexual. Essas comunidades simbólicas fortalecem-se na medida em que possibilitam a reivindicação de direitos particulares.

Tendo em vista a reconfiguração do poder do Estado, é necessária uma mudança de postura, para que passe a ser identificado como ator nas violações de direitos humanos as ações daqueles que detêm o poder econômico para transformar o Estado em mero instrumento dos seus interesses.

\section{Conclusão}

Percorrido o caminho proposto de interconexão entre a proteção dos direitos humanos e seus dilemas face à globalização econômica, reconfigurando as características tradicionais do Estado, é tempo de concluir.

A globalização possui diversas facetas e âmbitos de alcance. Esse fenômeno é responsável pela constante transformação do local frente à influência do universal, afetando as ciências, artes, cultura e relações sociais. As fronteiras do globo se abrem para um fluxo maior de informações, transportes, pessoas e capital. Porém, a globalização 
e o acesso a essa liberdade de fluxo não são universalizados de modo uniforme. Os benefícios desse fenômeno não são compartilhados.

É no âmbito econômico que o fenômeno da globalização encontra sua maior pujança. Desde o fim da Guerra Fria, o capitalismo e a ideologia do neoliberalismo firmaram-se como a principal forma de atuação do Estado, cuja atuação de promoção do bem-estar social objetivo fundante do Estado moderno - se viu cada vez diminuída.

A reconfiguração do Estado cindiu ainda mais a já complexa relação entre os direitos humanos civis e políticos e os direitos humanos sociais, econômicos e culturais. Com o neoliberalismo e uma maior autonomia econômica, o capital financeiro não encontrou mais barreiras para obtenção dos seus lucros, com uma relativização cada vez maior dos direitos dos trabalhadores, tidos como sociais. Tais direitos passaram a ser regulados pela necessidade do mercado financeiro.

O que este trabalho expõe é que, ao contrário do discurso veiculado pelos defensores da globalização econômica enquanto detentora somente de efeitos benéficos, o aumento da pobreza e do fosso entre ricos e pobres é ignorado. O neoliberalismo não conseguiu demonstrar que os direitos sociais, econômicos e culturais serão alcançados através do respeito aos direitos civis e políticos e da observância, pelo Estado, do desenvolvimento econômico.

Mesmo após a crise de 2008 e a reinvenção dos limites do papel do Estado e da economia, o que se vê triunfar é a ótica capitalista neoliberal, que coloca os Estados a serviço do capital financeiro privado - novamente repartindo prejuízos e individualizando ganhos.

O Direito Internacional reflete a tendência neoliberal ao ignorar produtos da violência aos direitos de caráter social e econômico, ao passo que ações que violem a liberdade são maciçamente condenadas.

Para superação do atual modelo de globalização econômica, em que o ser humano é relegado em prol de benefícios financeiros, faz-se necessária a alteração da agenda do Direito Internacional, incorporando as proposições dos direitos humanos. É preciso reconhecer os direitos 
internacionalmente consagrados como unos e indivisíveis, e as determinações de caráter político, civil, social, econômico e cultural devem ser perseguidas de modo uniforme.

\section{Referências}

ANAND, R. P. New states and international law. 2. ed. Deli: Nagri Printers, 2008.

ANGHIE, Antony. Imperialism, sovereignty and the making of international law. Cambridge: Cambridge University Press, 2004.

ARENDT, Hannah. Da Violência. Trad. Maria Claudia Drummond. Disponível em: <http://www.libertarianismo.org/livros/harendtdv.pdf>. Acesso em: 12 nov. 2014.

ASKOLA, Heli. Globalization and human rights. In: CHOWDHURY, Azizur Rahman; BHUIYAN, Jahid Hossain (Orgs). An introduction to international human rights law. Boston: Brill, 2010. p. 101-118.

BARROS, Alberto Ribeiro Gonçalves. O conceito de soberania no 'Methodus'de Jean Bodin. Discurso: Departamento de Filosofia da FFLCH da USP, São Paulo, n. 27, p. 139-156, 1996.

BACHAND, Rémi. Critical approaches and the third world: towards a global and radical critique of international law. Disponível em: <http:// www.mcgill.ca/files/legal-theory-workshop/Bachand-3rd-world-criticalapproaches.pdf>. Acesso em: 08 abr. 2014.

BAUMAN, Zygmunt. Globalização: as consequências humanas. Trad. Marcus Penchel. Rio de Janeiro: Jorge Zahar, 1999.

BENAKOUCHE, Rabah. A transnacionalização do Capital. Revista de Administração e Empresarial, Rio de Janeiro, v. 20, n. 1, p. 79-90, jan./mar. 1980.

BENGOA, Juan. Prologo. In: TERRE des hommes. El derecho a la equidad: ética y mundialización social. Barcelona: Icaria Editorial, 1997. p. 21-32.

BONAVIDES, Paulo. Ciência e política. 10. ed. São Paulo: Malheiros, 2001. 
CERNY, Philip. Globalization and other stories: the search for a new paradigm for international relations. International Journal: Globalization, v. 51, n. 4, p. 617-637, 1996. Disponível em: <http:// www.jstor.org/stable/40203151>. Acesso em: 18 nov. 2014

CHIMNI, B. S. Third world approaches to international law: A manifesto. International Community Law Review. The Hague, Leiden, v. 8. n 1. p. 3-27, 2006.

COX, Robert. Global Perestroika. Socialist Regist Journal, Pontypool, v. 28, p. 26-43, 1992. Disponível em: <http:// socialistregister.com/index.php/srv/article/view/5606\#. VGMnNpDF9Kp>. Acesso em: 12 nov. 2014.

DELBRUECK, Jost. International Protection of Human Rights and State Sovereignty. Indiana Law Journal, Bloomington, v. 57, n. 4, p. 567578 Disponível em: <http://www.repository.law.indiana.edu/ilj/vol57/ iss4/3>. Acesso em: 18 nov. 2014.

DONNELLY, Jack. The social construction of international human rights. Relaciones Internacionales, Madrid, n. 17, p. 1-30, jun. 2011.

State Sovereignty and Human Rights. Denver, 2004. (Working paper n. 21). Disponível em: <http://www.du.edu/korbel/hrhw/ workingpapers/2004/21-donnelly-2004.pdf>. Acesso em: 12 nov. 2014.

\section{DUARTE, Écio Oto Ramos. O neoconstitucionalismo como} antipositivismo jurídico: uma teoria do direito e do estado em fase do cosmopolitismo jurídico. $221 \mathrm{f}$. Tese (Doutorado em Direito Constitucional) - Universidade de Fortaleza, Fortaleza, 2013.

FACHIN, Melina Girardi. Direitos humanos e desenvolvimento. Rio de Janeiro: Renovar, 2015.

FALK, Richard. Globalização predatória: uma crítica. Lisboa: Instituto Piaget, 2001.

FARIA, José Eduardo. Direitos humanos e globalização econômica: notas para uma discussão. Estudos Avançados, São Paulo, v. 11, n. 30, p. 44, ago. 1997. Disponível em: <http://www.scielo.br/scielo. 
php?script=sci_arttext\&pid=S0103-40141997000200004\&lng=en\&nrm =iso>. Acesso em: 15 dez. 2014.

FERRAJOLI, Luigi. A Soberania no mundo moderno: nascimento e crise do Estado Nacional. Trad. Carlo Coccioli. São Paulo: Martins Fontes, 2002.

FUKUYAMA, Francis. O Fim da História e o Último Homem. São Paulo: Rocco, 1992.

GIDDENS, Anthony. As consequências da modernidade. Trad. Raul Fiker. São Paulo: Editora Unesp, 1991.

. The globalization of modernity. In: HOLD, David; MCGREW, Anthony (Orgs). The global transformation debate: an introduction. Cambridge: Polity Press, 2000. p. 1-44.

MICKELSON, Karin. Rhetoric and rage: third world voices in international legal discourse. Wisconsin International Law Journal, Madison,V. 16, n. 2, 1998. p. 353-419.

MORAES, George Rezende; RAMINA, Larissa. Introdução ao estudo das TWAIL: aspectos gerais e conceitos do retorno ao terceiro mundo. In: DOTTA, Alexandre Godoy; GOMES, Eduardo Biacchi (Orgs.). Coleção direito e ciência na contemporaneidade. Curitiba: Instituto Memória, 2014. p. 265-277. v. 1.

MÜLLER, Friedrich. Que grau de exclusão ainda pode ser tolerado por um sistema democrático? Revista da Procuradoria Geral do Município de Porto Alegre, Porto Alegre, v. 14, ed. esp. p. 1-60, out. 2000.

NYAMU-MUSEMBI, Celestine. Towards an actor-oriented perspective on human rights. Sussex: Institute of Development Studies, 2002. (IDS Working Paper, n. 169).

PIOVESAN, Flávia. Democracia, Direitos Humanos e globalização econômica: desafios e perspectivas para a construção da cidadania no Brasil. Disponível em: <http://www.dhnet.org.br/direitos/militantes/ flaviapiovesan/piovesan_democracia_dh_global_economica_br.pdf > . Acesso em: 20 dez. 2014. 
. Direitos humanos e justiça internacional. 5. ed. São Paulo: Saraiva, 2014.

PRASHAD, Vijay. The darker nations: a people's history of the third world. Nova lorque: The New Press, 2007.

RAJAGOPAL, Balakrishnan. Derecho Internacional desde Abajo: el desarrollo, los movimientos sociales y la resistencia del tercer mundo. Bogotá: Ilsa, 2005.

. Locating the Third World in cultural geography: Third World Legal Studies. Valparaiso University of Law, Valparaíso, v. 15, n. 1-2, p. 1-20, 1999.

ROBINSON, William L. Capitalist globalization and the transnationalization of the State. In: LITTLE, Richard; SMITH, Michael (Orgs). Perspectives in world politics. 3. ed. London: Routledge, 2002. p. $210-229$.

SANTOS, Boaventura de Sousa. Direitos humanos, democracia e desenvolvimento. São Paulo: Cortez, 2013.

. Os direitos humanos na zona de contacto entre globalizações rivais. Cronos, Natal, v. 8, n. 1, p. 23-40, 2007. Disponível em: <http:// www.boaventuradesousasantos.pt/media/Direitos\%20humanos $\% 20$ globaliza\%C3\%A7\%C3\%B5es\%20rivais_Cronos2007.pdf>. Acesso em: 20 dez. 2014.

. Por uma concepção multicultural de direitos humanos.

Revista Crítica de Ciências Sociais, Coimbra, n. 48, p. 11-32, jun. 1997.

SEITA, Alex Y. Globalization and the convergence of values. Cornell International Law Journal, Ithaca, v. 30, n. 429, 1997. Disponível em: <http://ssrn.com/abstract=1692834>. Acesso em: 19 nov. 2014.

STIGLITZ, Joseph E. A globalização e seus malefícios. Trad. Bazán Tecnologia Linguística. São Paulo: Futura, 2002.

Recebido em: 07/05/2015

Aprovado em: 03/07/2015 